\title{
As estratégias 'para o seu filho ler': estudo do contrato de leitura da seção infantil da Zero Hora
}

\author{
LARA NiederaUer MACHAdo \\ Universidade Federal de Santa Maria (UFSM) - E-mail: laraniederauer@gmail.com \\ Graduada em Comunicação Social - Jornalismo pela UFSM
}

VIVIANE BORELLI Universidade Federal de Santa Maria (UFSM) - E-mail: viviborelli10@gmail.com Professora Doutora do curso de Comunicação Social - Jornalismo da UFSM

\begin{abstract}
Resumo
Este artigo investiga a relação que o jornalismo firma - através do estabelecimento de um contrato de leitura - com o seu leitor, mais especificamente com o leitor da seção Para o seu filho ler, do jornal Zero Hora, do Rio Grande do Sul. Para análise, opta-se pela semiologia de terceira geração (Verón, 2004), em que foram selecionados enunciados da seção a partir de um corpus de 111 exemplares. Concebe-se que o processo de midiatização estrutura as práticas sociais e afeta as lógicas de funcionamento dos outros campos (Fausto Neto, 2007). A seção enuncia a um leitor específico e também é responsável pelo destaque ou pelo silenciamento de determinados temas. Zero Hora institui modos singulares de dizer aos pais e aos filhos o que eles devem e podem ler.
\end{abstract}

\section{Palavras-chave}

Jornal, contrato de leitura, enunciação, leitor.

\begin{abstract}
This work investigates the relation established by journalism - through a reading contract - with its readers, specifically with the reader of the section Para o seu filho ler (For your child to read) in newspaper Zero Hora, from the state of Rio Grande do Sul, in Brazil. For the analysis, we choose the guidance of third generation semiology (Verón, 2004), in which we have selected enunciations of the section from a corpus of 111 samples. It is conceived that the process of mediatization structure social practices and affects the logical operation of the other fields (Fausto Neto, 2007). The section enunciates to a specific reader and is also responsible for the prominence or the silencing of certain themes. Zero Hora establishes unique ways to tell parents and children what they should and can read.
\end{abstract}

\section{Keywords}

Newspaper, reading contract, enunciation, reader.

Artigo recebido em 09/02/2013

Aprovado em 13/04/2013 
processo de midiatização trouxe uma nova forma de compreender o lugar de produção. As mídias passaram a se inserir na organização e no funcionamento das sociedades na medida em que as integraram, deixando de ser encaradas apenas como mediadoras ou como fabricantes de produtos a serem consumidos pelas massas. Maria Cristina Mata (1999) destaca que elas são produtoras de sentidos e não simples meios de informação, a partir do momento em que o conceito 'massa' torna-se insuficiente para explicar fenômenos observados nas sociedades atuais. Portanto, as mídias tornam-se fundamentais na estruturação das práticas sociais ao integrarem o cotidiano dos indivíduos, uma vez que podem se assumir como fonte de informação, entretenimento ou construtores de imaginários: "É definida como uma nova matriz que se funda em novas racionalidades com as quais realiza estratégias de produção de sentidos" (FAUSTO NETO, 2006, p. 08, grifo do autor).

Nesse contexto, o objetivo do artigo $^{1}$ é identificar particularidades e características específicas do contrato de leitura proposto pela seção infantil Para o seu filho ler (PSFL) do jornal gaúcho Zero Hora. Parte-se do pressuposto de que é por meio de enunciações singulares que o jornal contata aquele que julga e avalia ser o 'seu leitor'. No caso da seção infantil, questiona-se também em que medida ela é direcionada diretamente para as crianças ou para os assinantes de Zero Hora que poderiam repassar aos filhos. Ou seja, o processo de enunciação da seção $P S F L$ aponta para que tipo de leitor? E, a partir disso, questiona-se também que temas podem ou devem ser lidos nesse espaço específico.

O processo de enunciação é responsável por algumas dessas estratégias. Segundo Émile Benveniste (1989), é através dele que o homem relaciona-se com outros homens e com o mundo. Essa relação é percebida pelas marcas do discurso que, contextualizadas na instância da produção, permitem compreender a forma como o interlocutor encara e se relaciona com aquilo que enuncia. Além disso, Benveniste (1989) postula que são necessárias duas figuras que se portem como protagonistas da

$1 \mathrm{O}$ artigo foi adaptado a partir de paper submetido para avaliação ao XIV Congresso de Ciências da Comunicação na Região Sul 2013 e resulta de parte de trabalho de conclusão de curso em Comunicação Social - Jornalismo realizado no primeiro semestre de 2012. 
enunciação, 'eu' e 'tu' - aquele que enuncia e aquele a quem a enunciação é destinada.

Entretanto, a estruturação e a construção não são exclusivas às mídias, pois as interações sociais podem reconstituir e reconstruir esses imaginários. Uma das principais estratégias utilizadas para a produção de sentidos é o dispositivo de enunciação, inserido no processo enunciativo, que serve para "assegurar a sua validade para um público indiferenciado, independentemente da experiência, das opiniões, dos interesses dos indivíduos e dos grupos a que se destina” (RODRIGUES, 1994, p. 148). Isso é possível, pois esses dispositivos ancoram os discursos a determinados contextos.

Para Eliseo Verón (2004), estudar o dispositivo de enunciação, na mídia impressa, é estudar o contrato de leitura. É nesse processo que estão presentes as marcas que revelam as condições da produção de determinado discurso. É o contrato de leitura, também, que desponta o que é esperado daquele leitor-destinatário: o que se sabe sobre ele e como se espera que ele aja frente a esse processo.

O conceito de contrato de leitura implica que o discurso de um suporte de imprensa seja um espaço imaginário onde percursos múltiplos são propostos ao leitor; uma paisagem, de alguma forma, na qual o leitor pode escolher seu caminho com mais ou menos liberdade, onde há zonas nas quais ele corre o risco de se perder ou, ao contrário, que são perfeitamente sinalizadas (VERÓN, 2004, p. 236).

O contrato de leitura é a forma dos enunciadores pressuporem os seus leitores nas instâncias discursivas. Fala-se em pressupor, pois o receptor é ativo, tanto que Verón prefere o termo "reconhecimento" ao invés de recepção (VERÓN, 2004, p. 216).

Todo o texto necessita de alguém que o ajude a funcionar e, por isso, a noção da existência do leitor é fundamental no processo de produção. Assim, Umberto Eco (1986), estabelece o conceito de leitor-modelo:

Para organizar a estratégia textual o autor deve referir-se a uma série de competências que confiram conteúdo às expressões que usa. Ele deve aceitar que o conjunto de competências a que se refere é o mesmo a que se refere o próprio leitor. Por conseguinte, preverá um Leitor-Modelo (...) (ECO, 1986, p. 39) 
Estudos em Jornalismo e Mídia - Vol. $10 \mathrm{~N}^{\circ} \mathrm{I}$ - Janeiro a Junho de 2013

A previsão da existência de um leitor-modelo faz com o texto seja direcionado para construí-lo. Um produto midiático pode abarcar diferentes leitores e, consequentemente, diferentes contratos de leitura. A Agência de Notícias dos Direitos da Infância (Andi), em 2002, por exemplo, já notava e comemorava a existência de dispositivos, em jornais de grande circulação, dedicados às crianças, como Folhinha, do jornal Folha de São Paulo e Globinho, do jornal O Globo.

Em contrapartida a essa tendência da criação de suplementos, em 2006, o jornal Zero Hora criou uma seção, Para o seu filho ler (PSFL). Essa foi a resposta a um problema observado pelo jornalista Marcelo $\operatorname{Rech}^{2}$ em sua casa:

Ela [seção] surgiu a partir de uma observação pessoal quando meu filho mais velho, hoje com 15 anos, tinha sete anos. Ele viu uma notícia na TV que havia lhe chamado à atenção e no dia seguinte procurou a notícia no jornal, mas de largada não entendeu e descartou o jornal. Aí me deu o estalo de criar uma seção que traduzisse para crianças e pré-adolescentes alguns assuntos relevantes que estão em outras mídias, mas que precisam de uma abordagem diferenciada para serem compreendidos por crianças. O objetivo, naturalmente, era criar o hábito de leitura, mas também de permitir uma interação familiar a partir do jornal.

Ricardo Stefanelli, um dos responsáveis pela implementação da seção no jornal, explica que "PSFL surgiu justamente para fazê-las [as crianças] transitar pelas editoriais todas, sem colocá-las à parte - ao contrário, inseridas no jornal, para pegar gosto por ele também. A seção, por tabela, pode auxiliar a cativar novos leitores”3.

Por essa preocupação de abordar as mais diversas editorias, o jornal acaba optando por um dispositivo mais flexível: uma seção ao invés de um suplemento. Como consequência dessa escolha, PSFL não apresenta periodicidade fixa, sendo sua publicação condicionada a outros elementos (notícias, editorias).

A seção possui um projeto gráfico bem específico, diferenciando-se do resto do jornal. Há um selo especial com o nome Para o seu filho ler, que identifica o início, e

2 Diretor editorial dos jornais do Grupo RBS, Marcelo Rech, em entrevista concedida à autora no dia 15 de maio de 2012, por e-mail.

3 Diretor de redação do Diário Catarinense, Ricardo Stefanelli, em entrevista concedida à autora no dia

21 de abril de 2012, por e-mail. 
uma linha horizontal, que identifica o final. O texto também se distingue do padrão utilizado no resto do jornal: frequentemente os parágrafos são divididos em tópicos e o negrito é usado. Outra recorrência é o selo do patrocinador, o colégio João Paulo I, que pode ser considerado um coenunciador responsável pelo fechamento da seção. Sua presença funciona como uma espécie de assinatura ao que é dito anteriormente.

Adriano Rodrigues (1994), ao estudar os telejornais, destacou o dispositivo do discurso genérico, constituído por uma sequência de imagens e músicas que delimitam o formato do jornal, assim como uma moldura delimita uma pintura. Ao transpor essa ideia para o objeto de estudo, pode-se dizer que a seção é identificada por um discurso genérico composto por estes elementos: selo da seção, selo do patrocinador e forma linear na cor laranja.

\section{Percurso metodológico}

$\mathrm{O}$ artigo tem como objetivo identificar singularidades e características específicas do contrato de leitura da seção infantil do jornal Zero Hora. Visa-se, portanto, identificar as estratégias discursivas utilizadas pela seção para conquistar o leitor e analisar em que medida a seção 'fala' ao público infantil. Para isso, optou-se pela análise semiológica a partir da perspectiva de Eliseo Verón (2004) acerca da "semiologia de terceira geração" (VERÓN, 2004, p. 215) que se diferencia das semiologias antecessoras por abarcar os efeitos de sentido em seus estudos. O dispositivo de enunciação envolve, além do sentido do que é dito, a imagem das entidades discursivas enunciador e destinatário e a relação entre eles. Para o autor, o principal objetivo da análise semiológica é determinar, por meio de uma análise de produção, a posição de um enunciador e consequentemente identificar marcas que busquem atingir o leitor pelo reconhecimento.

A análise busca compreender as estratégias utilizadas pelo jornal para conquistar o seu leitor e os modos através dos quais a seção institui vínculos com ele. Nesse sentido, não se foca no texto em si, mas no dispositivo de enunciação, nas relações entre os diversos dispositivos - jornal, editoria, seção, título, imagens. 
Para análise do objeto, foram recolhidas, entre 31 de dezembro de 2010 e 30 de junho de 2011, todas as seções publicadas por Zero Hora. Para o seu filho ler aparece em 98 exemplares, num total de 111 seções. A escolha do período não teve a intenção de ser quantitativa, mas exploratória e intencional por questões de viabilidade e de acesso ao jornal.

A partir da leitura de todas as Seções recolhidas, observando-se recorrências e singularidades dos textos publicados, definiram-se quatro categorias de análise, com base nos conceitos trabalhados acerca do contrato de leitura que se efetiva através do dispositivo de enunciação. Portanto, essas categorias - Complementariedade, Direcionamento para crianças, O leitor na enunciação, Quem fala em Para o seu filho ler - emanaram do próprio corpus e foram construídas a partir do percurso teórico metodológico e do problema de pesquisa, uma vez que compreende-se que não se pode analisar os enunciados em si, mas o processo de enunciação e sua relação com o dispositivo jornal.

Para melhor estruturação da análise e sistematização dos dados, utilizam-se as expressões E1, E2 e assim por diante para designar os enunciados analisados.

\section{Complementariedade}

Uma das primeiras singularidades notadas diz respeito ao formato. A construção da maioria das Seções se dá através da contextualização de uma notícia. Isso reflete desde a escolha das pautas até o formato assumido por Para o seu filho ler.

Essa estratégia é fruto do próprio objetivo da criação da seção, como explica o jornalista Ricardo Stefanelli: "O Para o seu filho ler surgiu com a ideia de ajudar os pais a traduzirem assuntos obrigatórios, mas delicados e/ou complexos". Então, PSFL precisa ser análogo àquilo que é pauta para Zero Hora. É um local em que é possível ressaltar ou silenciar determinados temas e modos de dizer. Dos 111 exemplares, 94 são complementos de outras notícias.

$\mathrm{O}$ uso dessa estratégia é compreendido na medida em que se conhece o objetivo da criação da seção. Porém, esse mesmo objetivo acaba ceifando o leque 
daquilo que pode ser considerado pauta para esse dispositivo. Para o seu filho ler poderia ir mais longe e tratar de assuntos que são de interesse de seus leitores e que não são necessariamente pautas de Zero Hora. Na próxima categoria, ver-se-á que essa dificuldade vai tentar ser sanada através de outras estratégias.

Diz-se que $P S F L$ complementa uma notícia, pois ela precisa dessa para ter seu espaço garantido no jornal. Isso é reflexo da situação que originou a criação da seção: o episódio descrito por Marcelo Rech demonstra que o contrato de leitura do jornal, muitas vezes, não abarca a criança como leitor-modelo. Para sanar essa lacuna, criou-se PSFL.

A situação relatada pelo jornalista também pontua outro aspecto: o primeiro contato pode não ser feito diretamente com o texto de $P S F L$. A seção pode vir para explicar, contextualizar uma pauta que o leitor conhece através de outras mídias. O interesse pode também ser despertado por elementos como título e fotos. A partir desse primeiro contato, os leitores mirins são direcionados para a seção infantil.

\section{Direcionamento para crianças}

Apesar de a complementariedade ser mais recorrente, há, em Para o seu filho ler, a construção de enunciados, chamados aqui de matérias direcionadas, que são específicos para as crianças. Assim, a seção perde parte da hierarquização a outros dispositivos do jornal. Com essa relativa independência, surgem, nas páginas de Zero Hora, assuntos que são tratados como interessantes apenas 'para os filhos lerem'.

Nos 111 exemplares analisados, foram reconhecidas 17 matérias direcionadas. Para tentar entender a circunstância em que são apresentadas essas pautas, analisou-se cada um dos exemplares e notaram-se singularidades próprias de cada matéria e particularidades em relação àquelas seções que complementam notícias.

As matérias direcionadas apresentaram dois formatos diferentes. Há aquelas que não se diferem da seção que complementa uma notícia, em que a maior, se não a única, diferença é a não subordinação a um dispositivo. Apresentam, assim, texto não assinado, em tópicos e em negrito, uso de ilustrações e/ou fotos. 
Entretanto, essa forma não é unanimidade. Das singularidades, é possível traçar uma característica própria apresentada por algumas matérias direcionadas: ao serem direcionadas, adota-se o padrão de notícias utilizado em outras editorias de Zero Hora. Assim, apresentam título, lead, cartola e assinatura de um jornalista (variável).

Quanto aos assuntos abordados, a partir de leituras, é possível formar três tipos de pautas. Essa divisão é baseada naquilo que Zero Hora considera como valor notícia: curiosidade, utilidade e agenda.

As pautas de curiosidade reúnem as matérias que mais se assemelham com as que complementam uma notícia. Aqui, o que torna fatos pautas do Para o seu filho ler são as peculiaridades sobre um determinado assunto, como, por exemplo, a origem histórica do chamado dia dos bobos ("Primeiro de abril, o dia dos bobos", 01/04/2011).

Já as matérias que se encaixam no grupo de pautas de utilidade, geralmente, tratam de campanhas de cunho nacional que se propõem a discutir assuntos como trânsito, meio ambiente e solidariedade. A Campanha do Agasalho foi uma das pautas abordadas. A matéria veiculada em 14 de junho de 2011 trata de especificar o que é a campanha, onde são os pontos de recolhimento e o que pode ser doado. Contudo, como isso não garantiria que o direcionamento se justificasse, o enunciador trata de remeter a um leitor particular:

E1: "Se você tem blusões, camisetas, tênis, meias ou cobertas que já não usa mais ou que já estão muito curtos para o seu tamanho, peça ajuda a seus pais para separá-los e levá-los a um dos pontos de coleta de doações espalhados pelo Estado”. (“Começa a campanha do agasalho 2011”, 14/06/2011)

O propósito das matérias direcionadas que se enquadram no grupo das pautas de agenda é fornecer informações - que se acredita ser - de utilidade para o leitor. A matéria "Papai Noel e Coelhinho da Páscoa juntos" (23/04/2011) ilustra esse tipo de abordagem: mais que enfocar as comemorações da Páscoa na serra gaúcha, tem por objetivo publicizar data, horário e local das atrações. 
Ao direcionar a origem do dia dos bobos, o início da Campanha do Agasalho e a programação das comemorações da Páscoa, Zero Hora pressupõe que seu leitormodelo, aquele que é enunciado como pai da criança que lê Para o seu filho ler, ou já tem esse conhecimento ou não se interessa por essa pauta.

O formato matéria direcionada surge como uma independência em relação a outros dispositivos que Para o seu filho ler comumente está atrelado. Abordaria, portanto, aquilo que é interessante, desconhecido e curioso para o leitor-modelo infantil. Mas como delimitar essas pautas? Observa-se, nas matérias direcionadas, ocorrência de temas que perfeitamente caberiam a todos os leitores de Zero Hora, sejam eles crianças ou adultos. O que acaba por delimitar o leitor-modelo é a convocação desse leitor particular, como visto em E1. E é essa estratégia que vai ser analisada a seguir.

\section{O leitor na enunciação}

A terceira recorrência notada demanda do próprio objetivo da seção Para o seu filho ler: ajudar os pais leitores de Zero Hora a traduzirem para seus filhos assuntos que estão presentes nas mídias. Isso ocorre pela própria enunciação, pois é com ela que o jornal impresso lida.

Para construir o leitor-modelo, o enunciador estabelece operações discursivas que permitam reconhecer o lugar desse leitor e que ele próprio se reconheça. Uma das estratégias utilizadas é a criação do texto a fim de a criança identificar menções a situações que fazem parte de seu dia a dia, segundo julgamento do enunciador, como referências à escola e família.

E2: "Este é um papo que já vem de longe, nem de quando seu pai era guri, mas da época em que o seu avô ia à escola". ("Rivalidade Gre-Nal", 15/05/2011)

E3: "Se você tiver qualquer dúvida, chame o seu pai ou o seu professor preferido para uma conversa”. (“Converse com seus pais ou professor”, 08/04/2011) 
As referências ao leitor-modelo também podem ser conseguidas através de embreantes pessoais, como classifica Dominique Maingueneau (2008). Esses embreantes são exemplificados pelo uso recorrente do "você" e dos pronomes possessivos "seu" e "teu”. Esses pronomes referem-se ao próprio leitor, como mostra o E3: "seu pai ou o seu professor", em que denota o pai e o professor daquele que lê.

Há também referências às situações que o jornal julga fazer parte do cotidiano desse leitor-modelo. São exemplos:

E4: "Todos os anos você aguarda ansiosamente pela chegada da Páscoa." (“Como saber a data”, 13/01/2011)

E5: "Quando você vai para a praia e passa por Osório, você já deve ter visto imensas torres que parecem esses cata-ventos gigantes." ("A força do vento", $31 / 03 / 2011)$

Através desses dois enunciados é possível traçar algumas nuances que mostram o que jornal Zero Hora, como enunciador, espera do leitor-modelo de Para o seu filho ler: ele é uma criança que comemora datas cristãs e que deve viajar com frequência para o litoral gaúcho.

Em E5 é possível notar outra forma dessa mesma estratégia: ilustrar com elementos que a criança conhece aquilo que lhe é desconhecido. Desse modo, as torres que servem para a produção de energia eólica tornam-se "cata-ventos gigantes", tal como a soma do Produto Interno Bruto é formada por:

E6: “(...) a roupa que a sua mãe compra, as casas novas construídas, a mensalidade da escola (...)" (“O PIB”, 04/03/2011).

E a função da previsão do tempo se resume a algo imediato: 
E7: “(...) para que você possa saber se amanhã poderá sair de manga curta ou se o melhor mesmo é levar um casaco" (“Curiosidades do clima”, 09/06/2011).

Lidar com o uso dessa estratégia de 'tradução' para o mundo da criança tornase muito difícil na medida em que a superestimação ou a subestimação das competências desse leitor podem ter consequências determinantes para as relações presentes no processo de enunciação.

De um lado é necessário afirmar que, se o enunciador não utiliza certas estratégias como essa, a seção acaba se tornando de difícil compreensão e não alcança o seu objetivo. Essa situação demonstraria um contrato de leitura falho que dá grande valor às competências que nem sempre o seu leitor possui. Como consequência máxima, esse sujeito que lê pode abandonar o texto. Isso vai de encontro com a noção de jornalista como operador semântico discutida por Lorenzo Gomis (1991): frente a uma realidade bruta, o jornalista deve manipulá-la linguisticamente para criar uma mensagem a ser interpretada em um determinado código por um determinado leitor.

Contudo, por outro lado, essas estratégias podem acabar subestimando essas competências e apenas reproduzindo aquilo que já é sabido. A consequência é um texto infantilizado que não leva um conhecimento novo à criança. Como detectado pela Andi (2002), o dispositivo direcionado não deve se diferenciar apenas pelo uso de cores e pelas brincadeiras impressas, mas deve ser o lugar onde o leitor entra em processo formador.

\section{Quem fala em Para o seu filho ler}

Um dos primeiros efeitos do enunciado é indicar a autoria, visto que o processo de enunciação prevê a existência de um sujeito enunciador, o 'eu'. Passa-se agora para a análise de quem fala em Para o seu filho ler.

A primeira constatação a ser feita é a de que o enunciador, na seção, é mutável. No corpus, detectou-se que ele pode ser de quatro tipos diferentes: jornal, jornalista, criança ou especialista. 
Diferente da maioria das notícias e matérias que constituem Zero Hora, a seção Para o seu filho ler predominantemente não é assinada. Dos 111 exemplares colhidos, 106 não são assinados, sendo-os delegada uma autoria que aponta para o próprio dispositivo jornal. Essa autorreferencialidade é produto do processo de midiatização no qual o jornal toma para si a posição de enunciador e passa a ser encarado como produtor e organizador de sentidos. Zero Hora assume esse papel quando determina o que e como vai ser enunciado, pressupõe seu leitor e refere algo que já faz parte do universo dessa criança. Para tal, acredita não ser necessária a nomeação dos enunciadores. $\mathrm{O}$ jornal, como dispositivo que faz parte de um contexto social, pode até produzir sentidos, mas, mais que isso, ratifica aquilo que crê ser do conhecimento de seu leitor.

O segundo enunciador identificado é o jornalista, o qual assina apenas quatro seções - todas matérias direcionadas. Esse enunciador nomeado, todavia, não se difere tanto do enunciador anterior, pois o jornalista é um enunciador do jornal. O que acontece aqui de diferente é que o jornalista ocupa o lugar do 'eu'. Por exemplo, André Mags que assina "Prédios coloridos contra acidentes" (12/05/2011) é quem se refere ao leitor, chamado de "você". Aquele a quem a enunciação acena sabe quem é que está enunciando uma vez que é nomeado.

A instituição de um enunciador através da assinatura da matéria não exclui que outros enunciadores constituam o texto. O próprio jornalista é cognominado, mas ele enuncia segundo a lógica do dispositivo jornal, assim como outros 'eu' que serão analisados a seguir.

As crianças, apesar de formarem o grupo que compõem o público de Para $o$ seu filho ler, caracterizam-se minimamente como enunciadores. Dessa forma, a seção muito mais se dirige às crianças do que dá voz a elas.

Em “Os campeões da Matemática” (19/05/2011), há três tipos de enunciadores nomeados e um deles são as crianças. Cinco alunos têm suas opiniões expressas fora do texto em uma coluna intitulada "De criança para criança". Isso mostra a opção de Zero Hora de utilizar a voz da criança mais como coadjuvante, e menos como protagonista.

Além da opinião dessas cinco crianças, o enunciador passa a ser uma criança 
apenas mais uma vez e em uma situação bem particular. No editorial "A verdade sempre” (07/02/2011), o jornal deixou a 'tradução' nas mãos de uma menina, membro do Conselho de Leitores. Assim, a enunciadora escreve aquilo que compreendeu do editorial publicado, explicando-o aos leitores.

No editorial reescrito é possível notar duas formas de autorreferência, propostas por Fausto Neto (2007): apresentar a realidade do jornal para o leitor a fim de aproximá-lo e descrever as ações da mídia frente a um acontecimento. A primeira acontece na chamada na capa e na nota introdutória que expõem o processo de construção a seção. Já a segunda é observada na escolha da pauta; o editorial tem por objetivo destacar a ação da mídia e dos jornalistas na revolução ocorrida no Egito:

E9: "Mesmo com toda a hostilidade e desrespeito, com que está sendo tratada, a imprensa está conseguindo fazer seu papel: mostrar a verdade, doa a quem doer!” (“A verdade sempre", 07/02/2011)

O importante foi referenciar o jornal e mostrar para as crianças o espaço de produção midiática, através de um fato. Esse exemplo mostra que, apesar de o enunciador ser aquele que mais se aproxima do leitor-modelo, o dispositivo jornal necessita autorreferenciar-se.

No entanto, tornar o enunciador uma criança é uma estratégia valorosa para que o leitor, provavelmente outra criança, identifique-se no texto, pois esse enunciador específico consegue fazer uso de algo que o enunciador jornal e adulto não são aptos nessa seção: a primeira pessoa do plural, 'nós'.

E9: "Estamos assistindo na televisão, ouvindo nos rádios e lendo em revistas e jornais, à grande revolução que está acontecendo no Egito". ("A verdade sempre", 07/02/2011)

Zero Hora opta por falar de si próprio e do seu campo de atuação e, assim, 
conferir a si credibilidade. A voz da criança é usada mais como uma estratégia do dispositivo do que como um ambiente de manifestação do leitor.

Além desses três enunciadores, há um último tipo que abrange diversos outros: os especialistas. No material analisado, foram encontrados os seguintes enunciadores: órgãos técnicos, pesquisadores, professores, leis, políticos e profissionais.

A presença de enunciadores, que não pertencem nem ao espaço de produção nem ao espaço de recepção, faz parte do que Rodrigues (1994) conceituou como dispositivo de enunciação. Para garantir que aquilo que enuncia seja aceito por leitores heterogêneos, o jornal deve ancorar os discursos a determinados contextos.

Algumas vezes, a nomeação da fonte se dá de forma generalista, não havendo identificação de seus nomes, da instituição a qual fazem parte e da cidade em que atuam. Informações geográficas e conhecimentos gerais se perdem com a nomeação genérica.

Além de fontes que credenciam o que está sendo pautado, os enunciadores aparecem mais como reforçadores do enunciador jornal. Tanto isso acontece que esses especialistas algumas vezes não são identificados no texto em si, mas fora dele. Dessa forma, o jornal assume para si a autoria do especialista, que só tem voz indireta.

Constatam-se quatro formas de enunciadores, contudo observa-se que três dessas categorias atuam a fim de garantir aquilo que o dispositivo jornal enuncia. Este toma a fala do especialista e da criança para si, já o jornalista é parte do dispositivo e, portanto, também enuncia pelo jornal.

\section{Considerações finais}

Para o seu filho ler é parte de um fenômeno observado pela Andi (2002) que consiste na criação, por parte de mídias já consolidadas, de suplementos e dispositivos direcionados para os leitores infantis.

A criação e a manutenção da seção estão inseridas num contexto em que a sociedade vive um processo de midiatização, pois as mídias têm papel preponderante na estruturação das práticas sociais. E, assim, o jornal passa a ser referência para os seus 
pequenos leitores e acaba, de alguma forma, fazendo parte de suas vidas.

Se o processo de midiatização deu um novo patamar às mídias, o de produtoras de sentido, é necessário que elas saibam lidar com isso, reinventando-se. Por isso, desenvolvem estratégias que garantam a sua manutenção como um dispositivo de referência junto à sociedade. A mídia concorre com as tradicionais instituições à medida que também determina modos de ver, avaliar o mundo e expressar opiniões.

Com a análise é possível perceber a relação de dependência estabelecida nas páginas de Zero Hora. Esse atrelamento acontece até mesmo quando a seção demonstra certa independência, seja de formato ou de voz que enuncia. Quando PSFL não está ligado a uma notícia, está vinculado a outras questões e dispositivos.

$\mathrm{O}$ contrato de leitura é eficaz na medida em que permite àquele leitor que denota se reconhecer. E é esse o maior esforço desempenhado pelo enunciador nas páginas de Zero Hora: garantir que o leitor se reconheça. O ponto forte do contrato de leitura construído na seção Para o seu filho ler é falar com a criança. Esse leitor-modelo é tão bem construído que os próprios enunciados apontam quem é e o que é esperado dele. Contudo, em detrimento à fixação tão explícita de um leitor, problemáticas que saiam desse contexto conhecido, mas que são igualmente importantes - como violência sexual, esporte, sustentabilidade e política - possuem pouca (ou nenhuma) incidência em PSFL.

A seção também é atravessada pelo fator comercial, no qual a presença de um patrocinador que encerra o texto (discurso genérico) gera um efeito de sentido que parece autorizar e codeterminar o que é dito pelo jornal. Dessa forma, o contrato de leitura firmado é atravessado também por questões comerciais, já que o jornal é uma empresa que precisa se sustentar economicamente.

Zero Hora, ao majoritariamente assumir o papel de enunciador, não permite que o leitor-modelo da seção assuma o lugar de produtor da enunciação. Mínimas vezes crianças assumiram a fala em Para o seu filho ler. E, mesmo quando enuncia, pode se observar situações em que a criança enunciadora assume a voz da autoridade midiática. A voz mirim poderia ser uma valorosa estratégia para chamar os leitores. 


\section{Referências bibliográficas}

AGÊNCIA DE NOTÍCIAS DOS DIREITOS DA INFÂNCIA; INSTITUTO AYRTON SENNA. A mídia dos jovens: esqueceram de mim - jornais brasileiros ignoram o potencial pedagógico dos cadernos infantis. Ano 6. n. 10, jun. 2002.

BENVENISTE, Émile. Problemas de Linguística Geral II. Campinas: Pontes, 1989.

ECO, Umberto. Lector in fábula - La cooperazione interpretativa nei testi narrativi. São Paulo: Perspectiva, 1986.

FAUSTO NETO, Antonio. Contratos de leitura: entre regulações e deslocamentos. Diálogos Possíveis, Salvador, ano 6, n. 2, p. 7-27, julho-dezembro/2007.

Midiatização, prática social - prática de sentido. Artigo apresentado na Rede Prosul Comunicação, Sociedade e Sentido, no seminário sobre midiatização. Unisinos, PPGCC, São Leopoldo, 2006. Texto avulso.

GOMIS, Lorenzo. Teoría del periodismo: como se forma el presente. Buenos Aires: Paidós, 1991.

MAINGUENEAU, Dominique. Análise de textos em comunicação. 5. Ed. São Paulo: Cortez, 2008.

MATA, Maria Cristina. De la cultura massiva a la cultura mediática. Diálogos de la comunicación. Lima: FELAFACS, p. 80-91, 1999.

RODRIGUES, Adriano Duarte. O dispositivo da enunciação. In: Comunicação e cultura: a experiência cultural na era da informação. Portugal: Presença, 1994.

VERÓN, Eliseo. Fragmentos de um tecido. São Leopoldo: Unisinos, 2004.

Este artigo e todo o conteúdo da Estudos em Jornalismo e Mídia

estão disponiveis em http://www.periodicos.ufsc.br/index.php/jornalismo/index

Estudos em Jornalismo e Mídia está sob a Licença Creative Commons 